\title{
Indolent growth of low-grade myofibroblastic sarcoma of the cheek mimics benign lesions: A case report and literature review
}

\author{
TESSHO MARUYAMA $^{1,2}$, TOSHIYUKI NAKASONE ${ }^{2}$, FUMIKAZU NIMURA ${ }^{1}$, \\ AKIRA MATAYOSHI $^{2}$, TOSHIHIRO KAWANO ${ }^{2}$, KAZUHIDE NISHIHARA $^{1,2}$ and AKIRAARASAKI ${ }^{1,2}$ \\ ${ }^{1}$ Department of Oral and Maxillofacial Functional Rehabilitation, Graduate School of Medicine, University of The Ryukyus; \\ ${ }^{2}$ Department of Oral and Maxillofacial Surgery, University Hospital of The Ryukyus, Nishihara, Okinawa 903-0215, Japan
}

Received October 22, 2015; Accepted January 19, 2017

DOI: $10.3892 / \mathrm{ol} .2017 .6020$

\begin{abstract}
Low-grade myofibroblastic sarcoma (LGMS) is a neoplasm of the soft tissue characterized by myofibroblastic differentiation. This type of tumor has been observed in various sites in the whole body, but frequently occurs in the head and neck region. It typically presents as a slow-growing painless mass, which is often mistaken for a benign lesion due to its indolent growth; however, LGMS is a malignant neoplasm. In the present study, a 43-year-old female presented with a 14-mm LGMS lesion in the buccal subcutaneous tissues of the buccinator muscle. The patient had initially noticed the lesion 2-months prior to presenting at the hospital. Following biopsy, the tumor was surgically resected and no recurrence or metastasis was observed during a follow-up time of 2 years. To the best of our knowledge, this case is the first report of LGMS located in the buccal subcutaneous tissue of the buccinator muscle. The present study a literature review of 55 cases of this tumor type in the head and neck region was conducted, revealing that the indolent growth of these lesions may contribute to a delay in diagnosis. The average time between the onset of clinical symptoms and hospital admission is 3.9 months, and this form of tumor is frequently misdiagnosed as a benign lesion. Therefore, the present study suggests that an incisional biopsy may be performed to rule out LGMS when clinicians encounter patients with the aforementioned indolent lesions anywhere in the body. In addition, the avoidance of
\end{abstract}

Correspondence to: Professor Akira Arasaki, Department of Oral and Maxillofacial Functional Rehabilitation, Graduate School of Medicine, University of The Ryukyus, 207 Uehara, Nishihara, Okinawa 903-0215, Japan

E-mail: arasaki@med.u-ryukyu.ac.jp

Abbreviations: LGMS, low-grade myofibroblastic sarcoma; WHO, World Health Organization; CT, computed tomography; MRI, magnetic resonance imaging; NA, not applicable; RT, radiotherapy; CHT, chemotherapy

Key words: low-grade myofibroblastic sarcoma, head and neck, buccal, cheek, biopsy, radiotherapy radiotherapy is recommended following resection of the LGMS tumor, as it may induce LGMS recurrence.

\section{Introduction}

Low-grade myofibroblastic sarcoma (LGMS) is a neoplasm of the soft tissue characterized by myofibroblastic differentiation, which may occur anywhere in the body but frequently occurs in the head and neck region $(1,2)$. Of those, the most common was the tongue (1). Owing to a previous lack of clear diagnostic criteria, the tumor is considered to more frequently occur than the number of times reflected in the literature (3). Furthermore, reports describing the clinical details such as tumor size, method of treatment, presence or absence of recurrence (local recurrence, regional recurrence and distant metastasis) and patient survival are sparse. Currently, despite being distinctly classified by the World Health Organization (WHO) (3), obtaining a differential diagnosis of this tumor from a benign lesion remains challenging (4). Owing to the scarcity of reported cases, the complete clinical picture of LGMS, including mortality rates, incidence rates, methods of treatment and risk factors, is unclear. Regarding recurrence, Yamada et al (4) reported that tumors larger than $3 \mathrm{~cm}$ tended to recur. Metastasis is reportedly rare (3). Therefore, definitive treatment criteria for LGMS remain unknown, and the requirement for postoperative radiotherapy or chemotherapy also remains undetermined. The tumor typically presents as a slow-growing painless mass that is often mistaken for a benign lesion due to its indolent growth; however, it is a malignant neoplasm that is able to recur or metastasize following an extended period of time (1). The present study details a case of a patient with LGMS of the buccal subcutaneous tissues on the buccinator muscle, and reviews 55 relevant cases of head and neck LGMS.

\section{Case report}

A 43-year-old Japanese female was referred to University Hospital of the Ryukyus (Okinawa, Japan) in May 2013 by her dentist due to the presence of a mass in the left buccal area that had developed over a 2-month period. The patient had noticed the lesion 2 months earlier, but did not present to the hospital for 2 months. There was no associated pain or paresthesia, 
and a systematic examination revealed that the patient was otherwise fit and healthy and reported no tobacco or alcohol use (4). The patient's family history indicated that her father had previously been treated for rectal cancer.

A physical examination revealed an elastic hard $13 \times 10 \mathrm{~mm}$ mass of the left buccal tissue with distinct margins. The overlying mucosa was normal in color and texture (Fig. 1) and no other causal factors underlying the presence of the mass were observed. The mucosa appeared healthy, no other lesions were observed and no palpable lymphadenopathy was detected in the neck of the patient.

Contrast-enhanced computed tomography (CT) and magnetic resonance imaging (MRI) revealed a $1.4-\mathrm{cm}$, well-defined mass in the left subcutaneous tissue of the cheek. The lesion was located on the buccinator muscle (Fig. 2, indicated by an arrow), and no other primary or metastatic lesions were detected in all examinations prior to surgery.

A biopsy revealed spindle cell proliferation. Therefore, an excisional biopsy was performed in order to remove the malignant neoplasm. Sections $(3 \mu \mathrm{m})$ were cut and stained with hematoxylin and eosin. The histopathological results revealed that the tumor was primarily composed of spindle-shaped cells presenting as diffusely infiltrative growth into the surrounding muscle tissues on a myxoid background. The tumor cells were predominately arranged in fascicles, whereas storiform patterns were focally observed. The tumor cells were atypical, with large round or spindle-like nuclei and ill-defined palely eosinophilic cytoplasm. The infiltration of cells around skeletal muscle fibers was also observed (Fig. 3A). Few mitotic cells ( $<2$ mitosis/10 high-power fields; Fig. 3B, indicated by an arrow) were observed and no tumor necrosis was observed (Fig. 3B). The lesions were low grade (5).

Immunohistochemical analysis was performed with the following antibodies: $\alpha$-smooth muscle actin (1:160; cat. no. M0851; Dako; Agilent Technologies, Inc., Santa Clara, CA, USA); mindbomb E3 ubiquitin protein ligase 1 (MIB-1; 1:100; cat. no. M7240; Dako; Agilent Technologies, Inc.); cluster of differentiation 34 (1:200; cat. no. QB-END/10; Novocastra Laboratories, Newcastle, UK); desmin (1:320; cat. no. M0760; Dako; Agilent Technologies, Inc.); caldesmon (1:100; cat. no. M3557; Dako; Agilent Technologies, Inc.); nuclear $\beta$-catenin $(1: 1,000$; cat. no. 610,154; BD Biosciences, San Diego, CA, USA); anaplastic lymphoma kinase (1:50; cat. no. M7195; Dako; Agilent Technologies, Inc.); S-100 protein (1:2,000; cat. no. Z0311; Dako; Agilent Technologies, Inc.); anti-pan cytokeratin antibody 1/3 (1:800; cat. no. M3515; Dako; Agilent Technologies, Inc.); and anti-cytokeratin CAM 5.2 (1:16; cat. no. 349205; BD Biosciences, San Jose, CA, USA). Sections $(3 \mu \mathrm{m})$ were cut and stained. The results identified that the majority of the spindle cells were focally immunoreactive for $\alpha$-smooth muscle actin (Fig. 4), and $<10 \%$ of the lesional cells stained positive for MIB-1 (Fig. 5). By contrast, immunostaining was negative for other markers, including cluster of differentiation 34 , desmin, caldesmon, nuclear $\beta$-catenin, anaplastic lymphoma kinase, $S-100$ protein and 2 markers of cytokeratin: anti-pan cytokeratin antibody $1 / 3$ and anti-cytokeratin CAM 5.2. Therefore, the histological and immunohistochemical features of LGMS were diagnosed.

Subsequently, re-excision was performed to obtain clear margins. No residual tumor tissue was observed in the

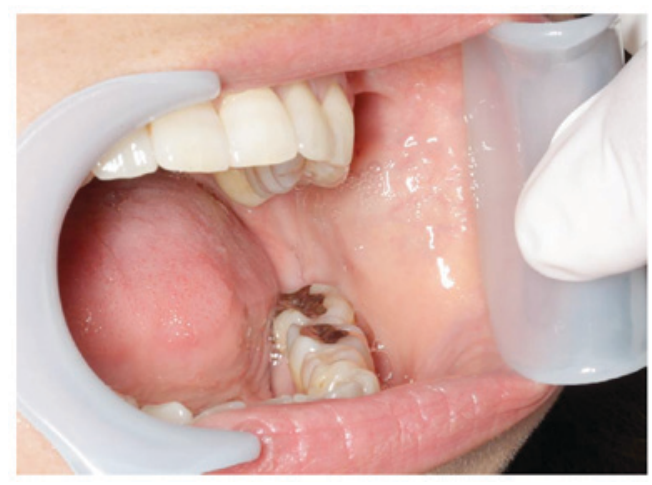

Figure 1. Intraoral image captured at the time of the initial patient diagnosis with low-grade myofibroblastic sarcoma. A physical examination revealed an elastic hard $13 \times 10 \mathrm{~mm}$ mass of the left buccal tissue with distinct margins. The overlying mucosa was normal in color and texture.

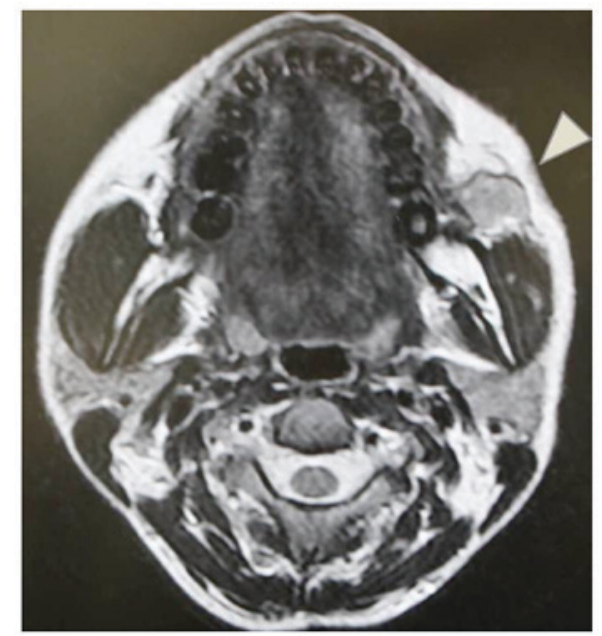

Figure 2. Magnetic resonance imaging revealed a $1.4-\mathrm{cm}$ well-defined mass in the left subcutaneous tissues of the cheek. The low-grade myofibroblastic sarcoma lesion was located on the buccinator muscle (indicated by the arrow).

re-excised specimen and no chemotherapy or radiotherapy was administered. At the end of the 2-year follow-up period, the patient was alive and healthy with no clinical or radiological signs of recurrence or metastasis (Fig. 6).

Written informed consent was obtained from the patient for the publication of this case report and all accompanying images. This case report was submitted for ethical review to the Ethics Committee of the University of the Ryukyus (Okinawa, Japan), who waived the requirement for review per institutional protocol, as the study does not contain content that required ethical approval. The Ethics Committee approved the submission and publication of the manuscript.

The first case of LGMS in the head and neck region was described in $1991(2,6)$. Literature reports published between 1991 and 2015 were identified using the search terms in PubMed and Google Scholar, excluding non-English language reports. A total of 55 cases were statistically analyzed. Gaussian distribution was confirmed by the Shapiro-Wilk test. Age was evaluated by one-factor analysis of variance (mean \pm standard deviation). The size of the tumor was evaluated by the Kruskal-Wallis test (median, minimum-maximum). Recurrence was evaluated by the Fisher's exact test (two-sided). 

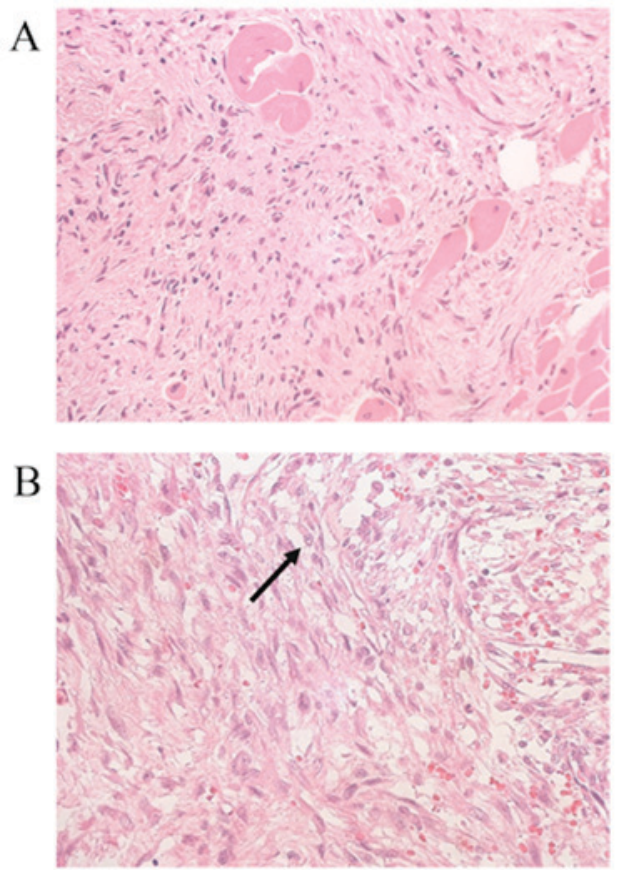

Figure 3. Histological results of the case. (A) The LGMS tumor cells were predominately arranged in fascicles, whereas storiform patterns were focally observed. Infiltration of cells around skeletal muscle fibers was observed (magnification, x20). (B) The LGMS tumor cells were round or contained spindle-like large nuclei, whereas the cytoplasm contained ill-defined, palely eosinophilic atypical cells with large nuclei. Few mitotic cells were observed ( $<2$ mitosis/10 high-power fields; indicated by arrow), and necrosis was not detected (magnification, x40). LGMS, low-grade myofibroblastic sarcoma.

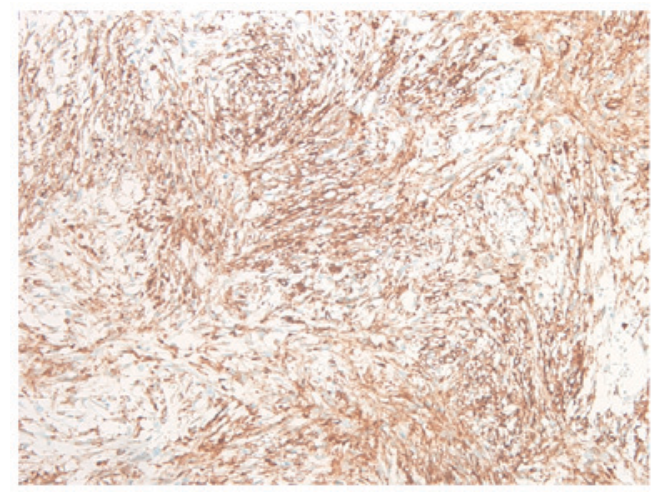

Figure 4. LGMS of the case. The spindle cells of the tumor were focally immunoreactive for $\alpha$-smooth muscle actin antibody (magnification, x20).

$\mathrm{P}<0.05$ was considered to indicate a statistically significant difference. Analyses were conducted with the use of SPSS for Windows version 22 (IBM SPSS, Armonk, NY, USA).

\section{Discussion}

The present study observed 2 important clinical issues. First, to the best of our knowledge, this case is the first report of LGMS in the buccal subcutaneous tissues of the buccinator muscle. Secondly, a literature review of 55 cases of this tumor in the head and neck region revealed that the indolent growth of these lesions may contribute to a delay in the diagnosis of LGMS: the studies reviewed indicated that the average time

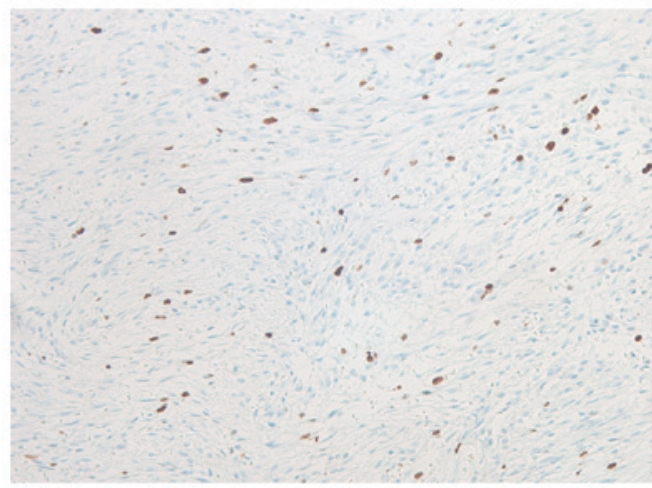

Figure 5.LGMS of the case. The spindle cells of the tumor were focally immunoreactive for mindbomb E3 ubiquitin protein ligase 1 (magnification, x20).

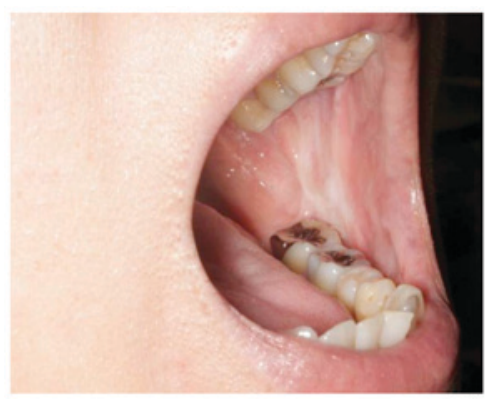

Figure 6. Intraoral image captured 2 years after treatment. The patient was disease-free at the final follow-up examination, 2 years following surgery. No recurrent lesion was identified.

between the onset of clinical symptoms and hospital admission is 3.9 months.

LGMS has been detected in various sites in the body, including the skin, extremities, trunk, breast, abdominal/pelvic cavity, kidney, vulva, pulmonary artery and bone (2,7-13), but frequently occurs in the head and neck region $(2,14,15)$. As presented in Table I, LGMS has been reported to occur in a number of locations in the head and neck region $(1,2,4,6,13,15-40)$. Of these, three cases of LGMS in the cheek have reported, including the present case, one case located at the nasolabial fold and one from the buccal mucosa $(16,23)$. The most common site was the tongue, followed by the mandible, neck, larynx, palate, maxilla and lips. LGMS was also observed in the gingiva, nasal/paranasal cavity, face, skull, external acoustic meatus, and deep tissue spaces, including the parapharyngeal space, as well as anywhere in the head and neck region (Table I).

In addition, the present study demonstrated that the indolent growth of LGMS may contribute to a delay in diagnosis. In the present literature review (Table I), the average time between the onset of clinical symptoms and hospital admission was 3.9 months (the average of this time is presented, with the exception of 'not applicable' (NA) cases, in Table I. LGMS is reported as a painless slow growing tumor with a relatively indolent course that mimics a benign lesion $(2,4)$. The majority of patients present with a painless swelling or an enlarged mass (3). These neoplasms arise predominantly in the subcutaneous and deeper soft tissue (3). The present study identified 55 cases of LGMS in the head and neck region 


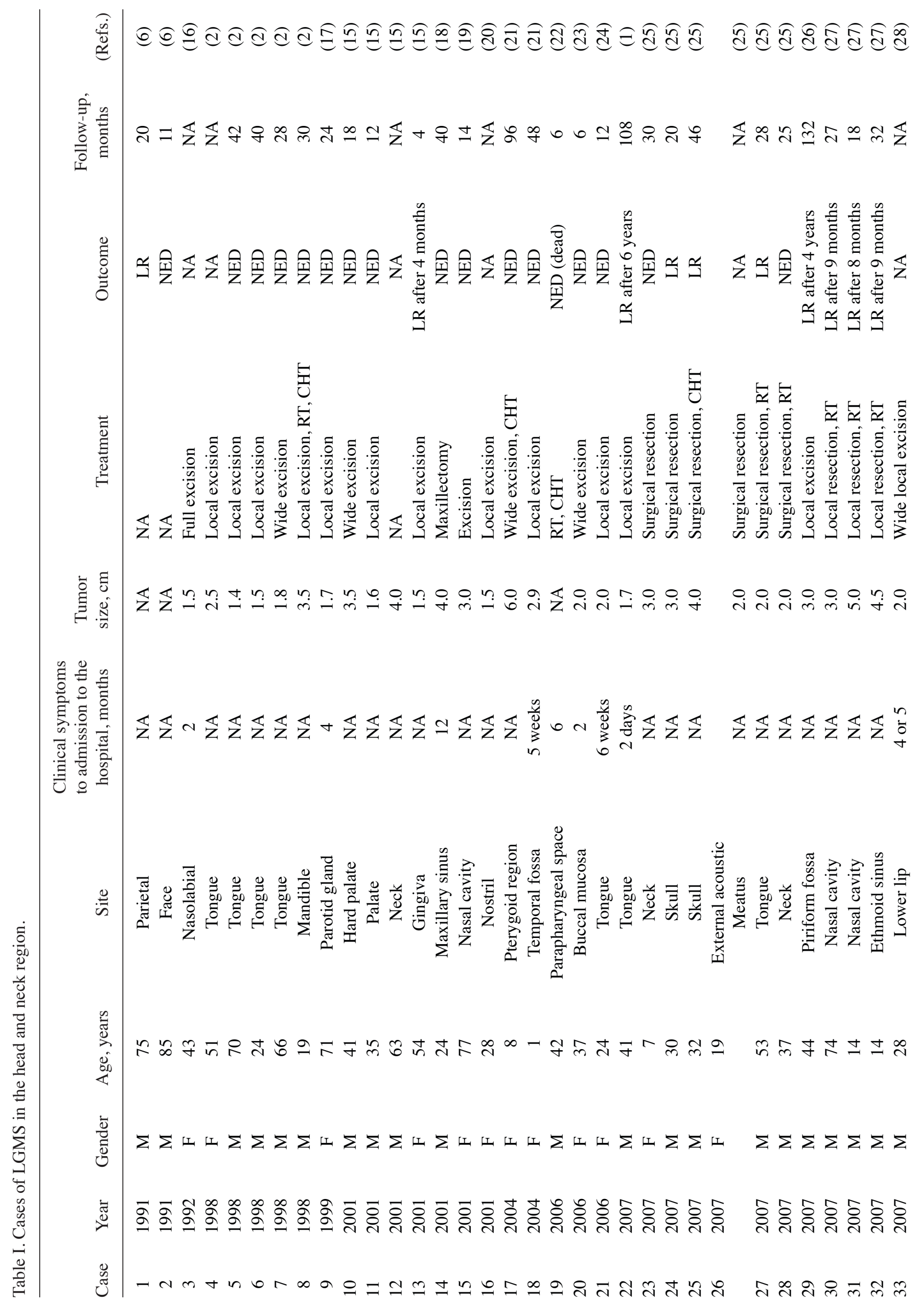




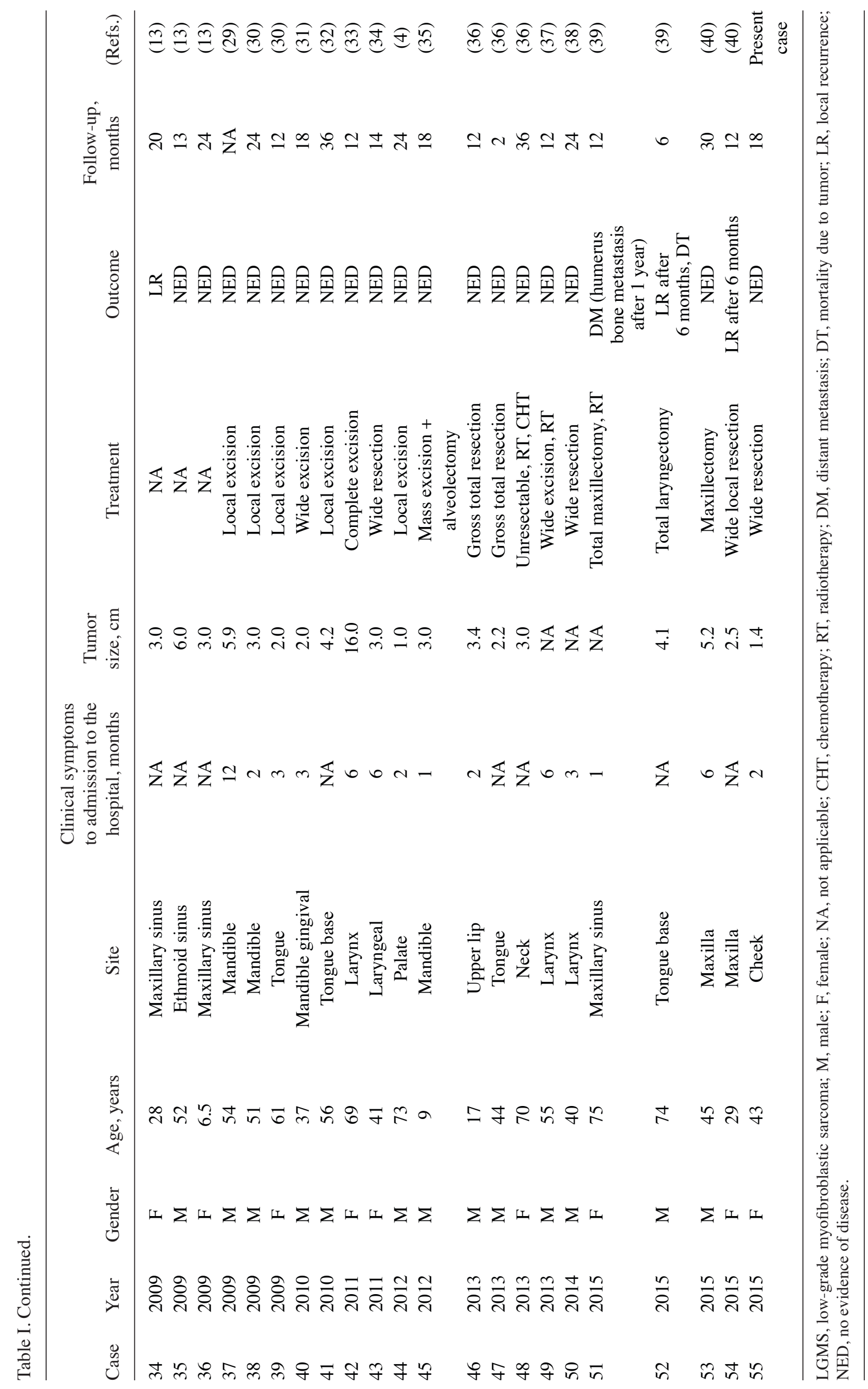


Table II. Recurrence rate and treatment of the LGMS instances reported in Table I.

\begin{tabular}{|c|c|c|c|c|}
\hline Treatment & $\begin{array}{c}\text { Number of } \\
\text { patients (male) }\end{array}$ & Mean age, years & $\begin{array}{l}\text { Mean size of } \\
\text { tumor, } \mathrm{cm}\end{array}$ & $\begin{array}{c}\text { Number of patients } \\
\text { with recurrence (rate, \%) }\end{array}$ \\
\hline Surgery only & $32(20)$ & $43.4 \pm 20.5$ & 3.1 & $6(18.8)$ \\
\hline Surgery + RT & $7(6)$ & $46 \pm 25.4$ & 3.3 & $5(71.4)$ \\
\hline Surgery + CHT & $2(1)$ & $20 \pm 17$ & 5 & $1(50)$ \\
\hline Surgery + RT + CHT & $1(1)$ & 19 & 3.5 & $0(0)$ \\
\hline Total & $42(28)$ & $42.1 \pm 21.5$ & 3.2 & $12(28.6)$ \\
\hline
\end{tabular}

The median size of tumor is calculated, except where NA is stated in Table I. LGMS, low-grade myofibroblastic sarcoma; RT, radiotherapy; CHT, chemotherapy.

Table III. Comparison of age, tumor size and recurrence between the treatment groups.

\begin{tabular}{|c|c|c|c|c|c|}
\hline & Surgery only $(n=32)$ & Surgery + RT (n=7) & Surgery + CHT $(n=2)$ & Surgery + RT + CHT $(n=1)$ & P-value \\
\hline Age (years) & $43.4 \pm 20.5$ & $46.0 \pm 25.4$ & $20.0 \pm 17.0$ & 19.0 & 0.312 \\
\hline Size of tumor $(\mathrm{cm})$ & $2.9(1.0-16.0)$ & $3.0(2.0-5.0)$ & $5.0(4.0-6.0)$ & $3.5(3.5-3.5)$ & 0.162 \\
\hline Recurrence & $6(18.8 \%)$ & $5(71.4 \%)$ & $1(50.0 \%)$ & $0(0.0 \%)$ & $0.016^{\mathrm{a}}$ \\
\hline
\end{tabular}

published in the English language, including the present case (Table I), with a mean patient age of 42.9 years (median patient age of 42.3 years; range, 1-85) and a male/female ratio of 3:2. Furthermore, the median age at the time of the diagnosis of LGMS in the head and neck region was determined to be younger, compared with that for all head and neck cancer (42.3 years and 60 years, respectively) (41). LGMS lesions are local, aggressive and characterized by frequent recurrence and metastasis, but exhibit a relatively indolent course, and tend to recur locally rather than metastasizing $(4,29)$. However, LGMS is able to metastasize to distant sites, including the left humerus and the cardiac region $(39,42)$. Therefore, disease management via wide excision of the tumor and long-term follow-up is suggested (25). In the present literature review, the rate of local recurrence and distant metastases were $29 \%$ $(14 / 49)$ and $2 \%$ (1/49), respectively. In total, 6/55 cases did not provide information regarding the incidence of recurrence or metastasis. None of the 55 studies reviewed reported regional recurrence.

Myofibroblasts were initially identified in 1971 as modified fibroblasts, and are considered to function in the contraction of granulation tissue (43). Myofibroblasts are morphologically and functionally varied, compared with fibroblasts (14), and form the principal component of a number of reactive and benign soft tissue lesions (44). In the past few decades, myofibroblasts have also been identified in malignant soft tissue tumors $(6,18)$. A number of types of sarcoma with predominant myofibroblastic differentiation have been identified and may be categorized into several well-defined clinicopathological entities (26), including LGMS and inflammatory fibroblastic tumor (44). Conversely, non-malignant myofibroblastic lesions include nodular fasciitis and myofibroma (44).

Various studies have provided a detailed analysis of LGMS to date $(2,4,13,15,25)$. The criteria for the classification of LGMS lesions have historically been disputed (45); however, such masses have been distinctly reclassified in the 2013 WHO classification of Soft Tissue and Bone (Fourth Edition) (3). LGMS is sometimes misdiagnosed as a benign lesion $(4,31)$, and a fine-needle aspiration biopsy may be inappropriate because it can obscure the tumor $(22,29)$. Therefore, for the diagnosis of LGMS, incisional biopsy is appropriate (30). An incisional biopsy must be undertaken with caution (27), as if the correct areas are not sampled by the biopsy, including in small or superficial biopsy samples, misdiagnosis may occur owing to the diverse histological appearance of LGMS cells in tissues from the same tumor (27). Until the year 2007, 18 cases of LGMS in the head and neck had been reported (26), whereas by the end of 2015, a total of 55 cases had been identified (Table I), and the case reports of LGMS may continue to increase.

Regarding LGMS treatment, the value of post-operative radiotherapy or chemotherapy remains to be established. Ni et al (34) recommended that the treatment of LGMS include wide excision, with tumor-free margins and post-operative radiotherapy or chemotherapy if required. By contrast, certain reports have described that radiotherapy and chemotherapy are of uncertain clinical value because the tumor was unresponsive. These authors recommended surgical treatment, 
including excision along the free margin $(21,40)$. Table II presents the recurrence rate (includes metastasis) of the resectable LGMS cases listed in Table I (excluding those with treatments or outcomes indicated as NA) following surgical resection. The recurrence rate following surgery only, as well as following surgery and radiotherapy, was $18.8 \%$ (6/32) and $71.4 \%(5 / 7)$, respectively. The statistical analysis revealed that the treatment of surgery and radiotherapy significantly increased the rate of recurrence $(\mathrm{P}=0.016$; Table III). By contrast, the age and the size of tumor showed no bias between the treatments $(\mathrm{P}=0.312$ and 0.162 , respectively). According to the aforementioned results, the present study suggests that radiotherapy must be avoided following resection of LGMS, as this treatment may induce the recurrence of LGMS.

After a 2-year follow-up period, the patient was alive and healthy with no clinical or radiological evidence of recurrence or metastasis; however, the patient required further observation. In conclusion, to the best of our knowledge, the present case report is the first report of LGMS in the buccal subcutaneous tissue of the buccinator muscle. It is suggested that incisional biopsy be performed to eliminate LGMS when clinicians encounter patients with the aforementioned indolent lesions anywhere in the body. It is also suggested that radiotherapy is avoided following resection of LGMS, as radiotherapy may induce the recurrence of LGMS. Further reports, including long-term follow-up data and adequate clinical information, are required to develop novel treatment protocols for LGMS, and to prevent radiation-induced LGMS, which may be more common than previously considered.

\section{Acknowledgements}

The authors would like to thank the staff of the Department of Pathology, University Hospital of the Ryukyus, who contributed to patient diagnosis, and all medical staff at University Hospital of Ryukyus who contributed to the treatment and care of the present patient. In addition, the authors would like to thank Enago (www.enago.jp) for the English language review of the present study.

\section{References}

1. Jay A, Piper K, Farthing PM, Carter J and Diwakar A: Low-grade myofibroblastic sarcoma of the tongue. Oral Surg Oral Med Oral Pathol Oral Radiol Endod 104: e52-e58, 2007.

2. Mentzel T, Dry S, Katenkamp D and Fletcher CD: Low-grade myofibroblastic sarcoma: Analysis of 18 cases in the spectrum of myofibroblastic tumors. Am J Surg Pathol 22: 1228-1238, 1998.

3. Mentzel T: Low grade myofibroblastic sarcoma. In: World Health Organization classification of Soft Tissue and Bone. Fletcher CDM, Bridge JA, Hogendoorn P and Mertens F (eds) 4th edition. IARC Press, Lyon, pp85-86, 2013.

4. Yamada T, Yoshimura T, Kitamura N, Sasabe E, Ohno S and Yamamoto T: Low-grade myofibroblastic sarcoma of the palate. Int J Oral Sci 4: 170-173, 2012.

5. Guillou L, Coindre JM, Bonichon F, Nguyen BB, Terrier P, Collin F, Vilain MO, Mandard AM, Le Doussal V, Leroux A, et al: Comparative study of the national cancer institute and french federation of cancer centers sarcoma group grading systems in a population of 410 adult patients with soft tissue sarcoma. J Clin Oncol 15: 350-362, 1997.

6. Eyden BP, Banerjee SS, Harris M and Mene A: A study of spindle cell sarcomas showing myofibroblastic differentiation. Ultrastruct Pathol 15: 367-378, 1991.

7. Diaz-Cascajo C, Borghi S, Weyers W and Metze D: Fibroblastic/myofibroblastic sarcoma of the skin: A report of five cases. J Cutan Pathol 30: 128-134, 2003.
8. Roth TM, Fratkin J, Woodring TC and McGehee RP: Low-grade myofibroblastic sarcoma of the vulva. Gynecol Oncol 92: 361-364, 2004.

9. Watanabe K, Ogura G, Tajino T, Hoshi N and Suzuki T: Myofibrosarcoma of the bone: A clinicopathologic study. Am J Surg Pathol 25: 1501-1507, 2001.

10. Humphries WE III, Satyan KB, Relyea K, Kim ES, Adesina AM, Chintagumpala $M$ and Jea A: Low-grade myofibroblastic sarcoma of the sacrum. J Neurosurg Pediatr 6: 286-290, 2010.

11. Morgan PB, Chundru S, Hatch SS, Hawkins HK, Adegboyega PA and Eltorky MA: Uncommon malignancies: Case 1. Low-grade myofibroblastic sarcoma of the breast. J Clin Oncol 23: 6249-6251, 2005

12. Tavora F, Miettinen M, Fanburg-Smith J, Franks TJ and Burke A: Pulmonary artery sarcoma: A histologic and follow-up study with emphasis on a subset of low-grade myofibroblastic sarcomas with a good long-term follow-up. Am J Surg Pathol 32: 1751-1761, 2008.

13. Meng GZ, Zhang HY, Zhang Z, Wei B and Bu H: Myofibroblastic sarcoma vs nodular fasciitis: A comparative study of chromosomal imbalances. Am J Clin Pathol 131: 701-709, 2009.

14. Tomasek JJ, Gabbiani G, Hinz B, Chaponnier C and Brown RA: Myofibroblasts and mechano-regulation of connective tissue remodeling. Nat Rev Mol Cell Biol 3: 349-363, 2002.

15. Montgomery E, Goldblum JR and Fisher C: Myofibrosarcoma: A clinicopathologic study. Am J Surg Pathol 25: 219-228, 2001.

16. Eyden BP, Christensen L, Tagore V and Harris M: Myofibrosarcoma of subcutaneous soft tissue of the cheek. J Submicrosc Cytol Pathol 24: 307-313, 1992.

17. Bisceglia M and Magro G: Low-grade myofibroblastic sarcoma of the salivary gland. Am J Surg Pathol 23: 1435-1436, 1999.

18. Bisceglia M, Tricarico N, Minenna P, Magro G and Pasquinelli G: Myofibrosarcoma of the upper jawbones: A clinicopathologic and ultrastructural study of two cases. Ultrastruct Pathol 25: 385-397, 2001.

19. Kondo S, Yoshizaki T, Minato H, Horikawa I, Tatsumi A and Furukawa M: Myofibrosarcoma of the nasal cavity and paranasal sinus. Histopathology 39: 216-217, 2001.

20. Chang SE, Choi JH, Sung KJ, Moon KC, Koh JK, Lee TJ, Ro JY and Silverman JS: A case of cutaneous low-grade myofibroblastic sarcoma. J Dermatol 28: 383-387, 2001.

21. Keller C, Gibbs CN, Kelly SM, Haller JR, White KS, Coffin CM and Lemons RS: Low-grade myofibrosarcoma of the head and neck: Importance of surgical therapy. J Pediatr Hematol Oncol 26: 119-120, 2004.

22. Takahama A Jr, Nascimento AG, Brum MC, Vargas PA and Lopes MA: Low-grade myofibroblastic sarcoma of the parapharyngeal space. Int J Oral Maxillofac Surg 35: 965-968, 2006.

23. Artopoulou II, Lemon JC, Clayman GL and Chambers MS: Stent fabrication for graft immobilization following wide surgical excision of myofibroblastic sarcoma of the buccal mucosa: A clinical report. J Prosthet Dent 95: 280-285, 2006.

24. Laco J, Simáková E, Slezák R, Tucek L, Mottl R, Spacek J and Ryska A: Low grade myofibroblastic sarcoma of tongue: A case report. Cesk Patol 42: 150-153, 2006.

25. Meng GZ, Zhang HY, Bu H, Zhang XL, Pang ZG, Ke Q, Liu X and Yang G: Myofibroblastic sarcomas: A clinicopathological study of 20 cases. Chin Med J (Engl) 120: 363-369, 2007.

26. Coyne JD: Low-grade myofibroblastic sarcoma of the piriform fossa: A case report with a literature review of a tumor with a predilection for the head and neck. Br J Oral Maxillofac Surg 45: 335-337, 2007.

27. Meng GZ, Zhang HY, Bu H, Yang GH, Zhang XL and Yang G: Myofibroblastic sarcoma of the nasal cavity and paranasal sinus: A clinicopathologic study of 6 cases and review of the literature. Oral Surg Oral Med Oral Pathol Oral Radiol Endod 104: 530-539, 2007.

28. Imanguli MM, Karai LJ, Shanti RM, Stewart DM and Brahim JS: Myofibroblastic tumor of the lower lip in a patient with X-linked hypogammaglobulinemia and isolated growth hormone deficiency: A case report. J Oral Maxillofac Surg 65: 1219-1222, 2007.

29. Niedzielska I, Janic T and Mrowiec B: Low-grade myofibroblastic sarcoma of the mandible: A case report. J Med Case Reports 10: 8458, 2009.

30. Demarosi F, Bay A, Moneghini L and Carrassi A: Low-grade myofibroblastic sarcoma of the oral cavity. Oral Surg Oral Med Oral Pathol Oral Radiol Endod 108: 248-254, 2009.

31. Montebugnoli L, Venturi M, Gissi DB, Flamminio F and Foschini MP: Low-grade myofibroblastic sarcoma of the gingiva. BMJ Case Rep 2010: bcr0720103166, 2010. 
32. Mori T, Shimane T, Hayashi T, Uzuki A, Ikenoya Y, Akiyama R, Egawa $S$ and Sanbe T: Low-grade myofibroblastic sarcoma at the base of the tongue. Showa Univ J Med Sci 22: 239-243, 2010.

33. Covello R, Licci S, Pichi B, Spriano G, Vidiri A, Morelli L and Rosenberg AE: Low-grade myofibroblastic sarcoma of the larynx. Int J Surg Pathol 19: 822-826, 2011.

34. Ni C, Xu YY, Zhou SH and Wang SQ: Differential diagnosis of inflammatory myofibroblastic tumor and low-grade myofibroblastic sarcoma: Two case reports with a literature review. J Int Med Res 39: 311-320, 2011.

35. Park KR, Jang HW, Won JH, Kim HS, Cha IH and Kim HJ: Myofibroblastic sarcoma of the mandible: a case report. J Korean Assoc Oral Maxillofac Surg 38: 240-244, 2012.

36. Cai C, Dehner LP and El-Mofty SK: In myofibroblastic sarcomas of the head and neck, mitotic activity and necrosis define grade: A case study and literature review. Virchows Arch 463: 827-836, 2013

37. Khosla D, Yadav BS, Kumar R, Ghoshal S, Vaiphei K, Verma R and Sharma SC: Low-grade myofibroblastic sarcoma of the larynx: A rare entity with review of literature. J Cancer Res Ther 9: 284-286, 2013.

38. Kordač P, Nikolov DH, Smatanová K and Kalfeřt D: Low-grade myofibroblastic Sarcoma of the larynx: Case report and review of literature. Acta Medica (Hradec Kralove) 57: 162-164, 2014.
39. Guillermo GO, Ignacio AG, Adriana SAB, Rocío SB, Fátima MP and Modesto AF: Low-grade myofibroblastic sarcoma. Two rare tumors in two rare locations. Rev Esp Cir Oral Maxillofac 37: 108-112, 2015.

40. Qiu JY, Liu P, Shi C and Han B: Low-grade myofibroblastic sarcomas of the maxilla. Oncol Lett 9: 619-625, 2015.

41. Baxi SS, Pinheiro LC, Patil SM, Pfister DG, Oeffinger KC and Elkin EB: Causes of death in long-term survivors of head and neck cancer. Cancer 120: 1507-1513, 2014.

42. Oylumlu M, Yildiz A, Ercan S, Oylumlu M and Davutoglu V: Cardiac metastasis of a low-grade myofibroblastic sarcoma. Echocardiography 31: E1-E4, 2014.

43. Gabbiani G, Ryan GB and Majne G: Presence of modified fibroblasts in granulation tissue and their possible role in wound contraction. Experientia 27: 549-550, 1971.

44. Fisher C: Myofibroblastic malignancies. Adv Anat Pathol 11: 190-201, 2004.

45. Lagace R, Semir TA, Gabianni G and Schurch W: Myofibroblastic sarcoma. Am J Surg Pathol 23: 1432-1438, 1999. 